\title{
化学気相析出法による $\mathrm{NiO} / \mathrm{SiO}_{2}$ 粒子の調製 $^{\dagger}$
}

\author{
大井 浩 ${ }^{*} \cdot$ 大槻淳幸 $^{* *}$. 矢野元威・原納淑郎
}

\section{大阪市立大学工学部 応用化学教室 ${ }^{\dagger+}$}

含浸法などの従来の方法で触媒調製を行うと，一般に その工程の繁雑さのため, 再現性良く目的の性能を有す る触媒を得ることか困難な場合がある。 そこで, 触媒有 効成分を高分散化し超微粒子金属触媒を再現性良く得る 有効な方法として, 先に噴霧熱分解法により $\mathrm{Ni} / \mathrm{SiO}_{2}$ 触

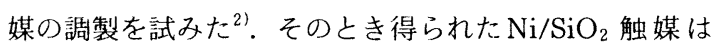
一次粒子直径が $30 \mathrm{~nm}$ 程度に凝集したアモルファス状の $\mathrm{SiO}_{2}$ 粒子群中に $20 \sim 80 \mathrm{~nm}$ の $\mathrm{NiO}$ 粒子として分散して おり, CO のメタネーション活性が従来の触媒比して高 いことを明らかにした ${ }^{21}$.また噴霧熱分解法では $\mathrm{NiO}$ 粒 子径は $\mathrm{Ni}$ 源である $\mathrm{NiCl}_{2}$ /メ夕ノールの噴第液滴径に支 配されることが明らかとなったので，本報では気相状 態の $\mathrm{NiCl}_{2}, \mathrm{SiCl}_{4}$ 抢よび空気を用いて気相熱分解を行い, $\mathrm{Ni} / \mathrm{SiO}_{2}$ 触媒の調製を試みた。

\section{実験装置およひ実験方法}

触媒調製 触媒前駆体である $\mathrm{NiO} / \mathrm{SiO}_{2}$ は，下式の 反応従って得られる.

$\mathrm{NiCl}_{2}+\mathrm{SiCl}_{4}+3 / 2 \mathrm{O}_{2} \rightarrow \mathrm{NiO} / \mathrm{SiO}_{2}+3 \mathrm{Cl}_{2} \quad(1)$

ここに調製した $\mathrm{NiO} / \mathrm{SiO}_{2}$ を水素により還元処理して $\mathrm{Ni} / \mathrm{SiO}_{2}$ 触媒を得た。触媒調製に用いた装置をFig. 1 亿 示す. 空気はコンプレサーCoより $7.0 \times 10^{-3} \mathrm{~m}^{3} / \mathrm{min}$ で 送入し, メタノール/ドライアイス浴に浸したトラップ $\mathrm{T}_{2}$ で乾燥空気として反応器入口 Laに導いた. $\mathrm{SiCl}_{4}$ 送入 用の窑素は $1.0 \times 10^{-3} \mathrm{~m}^{3} / \mathrm{min}$ の流量でメタノール/ドラ イアイス浴に浸したトラップ $\mathrm{T}_{1}$ で乾燥窒素とし， $273 \mathrm{~K}$ 亿保った恒温槽に浸した $\mathrm{SiCl}_{4}$ 飽和器 $\mathrm{Ss}$ を経て反応器入 [1] Ls に導いた。一方 $\mathrm{NiCl}_{2}$ 蒸気はトラップ $\mathrm{T}_{3}$ で精製乾 燥した $\mathrm{N}_{2}$ を反応器入口 $\mathrm{Ln}$ から導入した. 反応器はi.d. $\phi 30 \mathrm{~mm}$, 長さ $800 \mathrm{~mm}$ の石英製であり, $\mathrm{NiCl}_{2}$ 蒸発部 と反応部より成っている。 ての反応器の細部構造を Fig. 2 亿示す. 蒸発部の中の石英製ボートに, 約 $5 \mathrm{~g}$ 程度の 無水 $\mathrm{NiCl}_{2}$ を仕込み，所定量の $\mathrm{NiCl}_{2}$ 蒸気を発生させる ように電気炉 $\mathrm{Fe}$ で加熱する. 発生した $\mathrm{NiCl}_{2}$ 蒸気は内 管を通って反応部に送られる。一方 $\mathrm{SiCl}_{4}$ 抢よび空気は Ls およびLa より導入され, $\mathrm{NiCl}_{2}$ 蒸発部の外管を通っ

\footnotetext{
$†$ 1989年 6 月 1 日受理

†† 5558 大阪市住吉区杉本 $3-3-138$

* 雇用促進事業闷 大阪職業訓練校

** 小野薬品工業 (株)
}

て反応部に導かれる. てれら反応物は反応部で合一LEq. （1）の熱分解反応を行う.

反応生成物は反応器下流のコンデンサーCで泠却され, バグフィルターB1（B2）飞捕集した．未反応物気体はさ らに下流の $0.1 \mathrm{~N} \mathrm{HCl}$ の入ったスクラバーS で加水分解 した後, 沃素スクラバーI を経て大気に放出した。 反応 温度は前報 ${ }^{2}$ 同椂反応器軸方向に温度分布を有するので 反応器内の最高温度部を示す部分の温度を反応温度とし た。

典型的な試料調製条件を Table 1 亿示す. $\mathrm{NiCl}_{2}$ およ び $\mathrm{SiCl}_{4}$ の蒸気発生条件はそれぞれ $\mathrm{Schafer}^{4)}$ 抢よび Kearby ${ }^{4-7)}$ な゙の文献を参考にして実験的に定めた。

生成した試料の $\mathrm{Ni}$ 担持率は前報 ${ }^{21}$ 同様原子吸光法によ り決定した。ここで調製した試料は気相から析出させた 試料であると言う意味から G 頭に付けて表し，次に Ni の $\mathrm{N}$ を用い，その $\mathrm{Ni}$ 担持率を $\mathrm{X}$, 担体か $\mathrm{SiO}_{2}$ であるて とからSI, これらを合わせて GNXSI と表した。これら 試料の内 GN 11. 0SI を理学電機 2078 X線回折装置を用 いてXRD スペクトルを測定したとてろ, Fig. 3a 亿示 すように未反応の $\mathrm{NiCl}_{2}$ が残存するてとが明らかとなっ た．そこで約 $500 \mathrm{mg}$ の試料を約 $30 \mathrm{ml}$ の蒸留水で水洗 して再びXRD スペクトルを測定したとてろFig. 3 b示 すように $\mathrm{NiC}_{2}$ のスペクトルは除去された。 そてでての 洗浄後の試料の $\mathrm{Ni}$ 含有率 $\mathrm{Y}(\%)$ を原子吸光法で測定し, GNYSI - $(W)$ と命名した。

試料のキャラクタリゼーション 水洗した約 100〜 $150 \mathrm{mg}$ の試料を用いて，水素圧 $0.1013 \mathrm{MPa}, 623 \mathrm{~K}$ で流 通型反応器を用いて $3 \mathrm{~h}$ 還元を行い，系内をそのままの 温度にして $1.013 \mathrm{~Pa}$ の真空で $3 \mathrm{~h}$ 排気したのち, 試料温 度を室温に戻し約 $0.0263 \mathrm{MPa}$ の水素を用いて化学吸着を 行いその吸着量を測定した. 乙の水素吸着量 $V_{H}[\mathrm{~mol} / \mathrm{g}]$ を基に, 単位重量当たりの $\mathrm{Ni}$ 露出面積 $S_{N i}\left[\mathrm{~m}^{2} / \mathrm{g}-\mathrm{Ni}\right]$, 平均粒径 $d_{N i}[\mathrm{~nm}]$, および分散度 $D[-]$ 求めた。

\section{実験結果およひ考察}

$\mathrm{NiCl}_{2}$ 掞よび $\mathrm{SiCl}_{4}$ の転化率 $\quad \mathrm{NiO} / \mathrm{SiO}_{2}$ は Eq. (1)に したがって生成する.てのような塩化物の酸化反応を追 跡する方法として $\mathrm{TiCl}_{4}$ の酸化反応の例

$$
\mathrm{TiCl}_{4}+\mathrm{O}_{2} \rightarrow \mathrm{TiO}_{2}+2 \mathrm{Cl}_{2}
$$

がある"．乙の方法は Eq. (2)の反応により発生する $\mathrm{Cl}_{2}$ 




Fig. 1 Schematic diagram of CVD appratus

$\mathrm{B}_{1}, \mathrm{~B}_{2}$ : Bag filter $\mathrm{C}$ : Cooling condensor Co : Air compresser

$\mathrm{E}$ : Evaporation zone for $\mathrm{NiCl}_{2} \quad \mathrm{~F}_{1}, \mathrm{~F}_{2}, \mathrm{~F}_{3}$ : Flow control valve

$\mathrm{Fe}:$ Furnace for evaporization of $\mathrm{NiCl}_{2} \mathrm{Fr}:$ Furnace for reaction,

I : Scrubber for $\mathrm{Cl}_{2}$ La : Inlet for Air $\mathrm{Ln}$ : Inlet for $\mathrm{N}_{2}$

Ls : Inlet for $\mathrm{SiCl}_{4} \quad \mathrm{~N}$ : Nitrogen cylinder $\mathrm{R}$ : Reactor

$\mathrm{S}$ : Scrubber for $\mathrm{HCl}$ trap $\mathrm{Ss}$ : Saturator for $\mathrm{SiCl}_{4}$

$\mathrm{T}_{1}, \mathrm{~T}_{2}, \mathrm{~T}_{3}:$ Methanol/Dryice cold trap

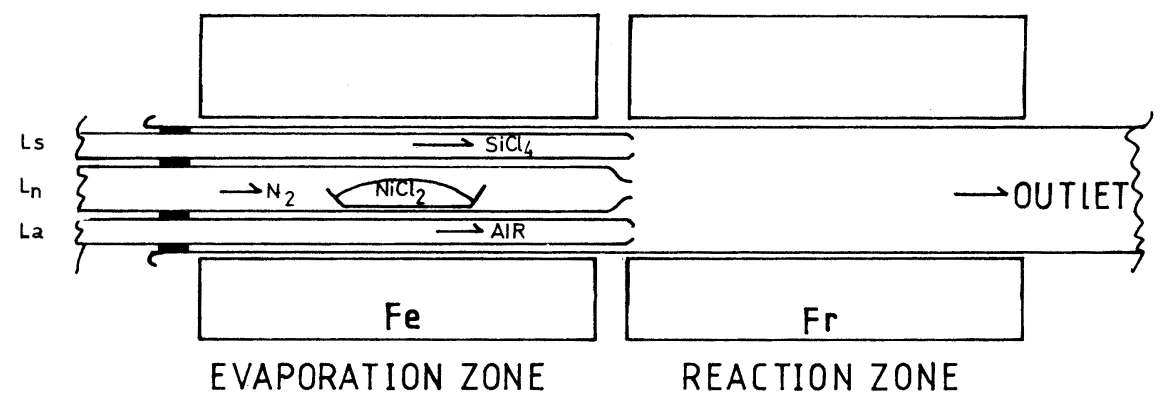

Fig. 2 Detail of evaporization and reaction zone

を沃度滴定法で測定している。しかし，本報のように $\mathrm{NiCl}_{2}$ と $\mathrm{SiCl}_{4}$ と二種類の塩化物が存在する場合は，乙 の方法では塩素は両者の何れの側から発生したか区別で きない，そこで $\mathrm{Cl}_{2}$ が $\mathrm{pH}<3$ の酸性溶液中では解離し ないととを利用して $\mathrm{HCl}$ と $\mathrm{Cl}_{2}$ を別々に分析した。すす わち，第一段目のスクラバーでは未反応 $\mathrm{SiCl}_{4}$ ガスは Eq.

（3）にしたがって加水分解する.

$$
\mathrm{SiCl}_{4}(\mathrm{~g})+2 \mathrm{H}_{2} \mathrm{O}(1) \rightarrow \mathrm{SiO}_{2}(\mathrm{~s}) \downarrow+4 \mathrm{HCl}(\mathrm{aq})
$$

こてに発生した HCl (aq) は反応終了後, 逆滴定量より測 定前の酸量を差引き定量した。乙の $\mathrm{HCl}$ 量の $1 / 4$ を反応 時間で除して単位時間当たりの $\mathrm{SiCl}_{4}$ 通過量 $b[\mathrm{~mol} / \mathrm{min}]$ を得た。後段には沃度溶液を満たしたスクラバーを設け， Eq. (1)により発生した遊離の $\mathrm{Cl}_{2}$ を定量した。こてに測 定された単位時間当たりの $\mathrm{Cl}_{2}$ 発生量を $a[\mathrm{~mol} / \mathrm{min}]$ と する．供給側の $\mathrm{SiCl}_{4}$ および $\mathrm{NiCl}_{2}$ の供給速度 $\alpha_{0}$ および
Table 1 Preparation condition of catalysts Catalyst $\mathrm{NiCl}_{2}$ vaporized Temperature $\mathrm{V}_{\mathrm{NiCl}_{2}}$ [K]

GN 6.0SI

1053

GN 11.0SI

GN $12.7 \mathrm{SI}$

1073

1083

1123

1143 $\left[10^{-3} \mathrm{~mol} / \mathrm{min}\right]$

GN 13.5S

GN 18.0SI

Flow rates of $\mathrm{SiCl}_{4}$ and air are $3.82 \times 10^{-3}$ and $6.25 \times 10^{-3}$ $\mathrm{mol} / \mathrm{min}$, respectively, and reaction temperature is 1530 $\mathrm{K}$ for all experiments

$\beta_{0}[\mathrm{~mol} / \mathrm{min}]$ と気相反応による $\mathrm{SiO}_{2}$ および $\mathrm{NiO}$ の生成 量 $\alpha$ 执よび $\beta$ との間には,

$$
\begin{aligned}
& \mathrm{SiCl}_{4}+\mathrm{NiCl}_{2}+\mathrm{O}_{2} \rightarrow \mathrm{SiO}_{2}+\mathrm{NiO}+\mathrm{Cl}_{2} \\
& \left(\alpha_{0}-\alpha\right) \quad\left(\beta_{0}-\beta\right) \quad(\alpha) \quad(\beta) \quad(2 \alpha+\beta)
\end{aligned}
$$




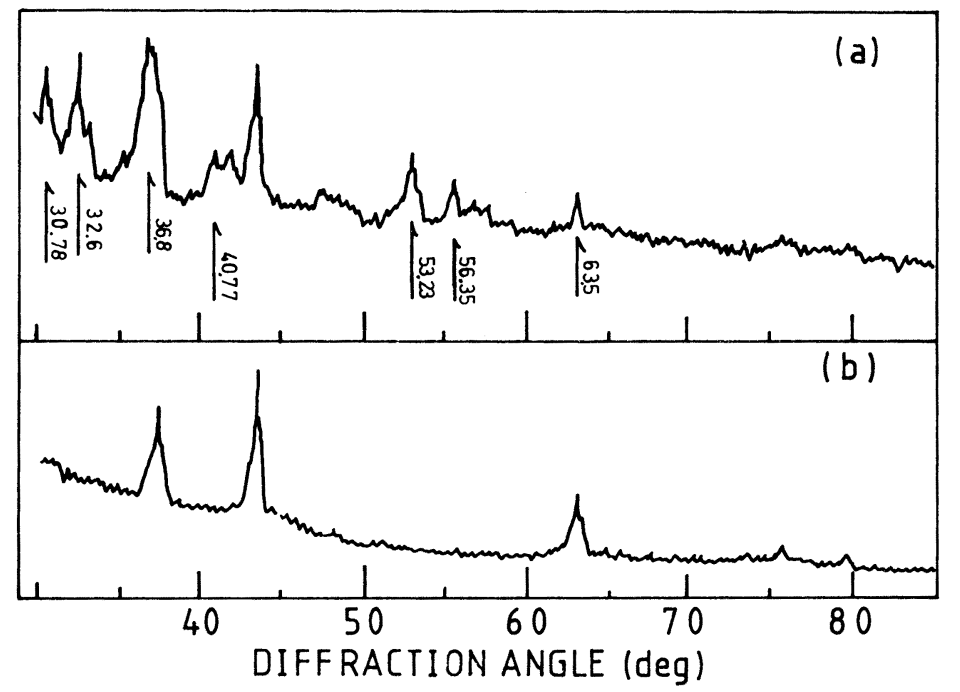

Fig. 3 X-ray diffraction pattern of unwashed (GN11.0 SI)

(a) and washed (GN 5.3 SI- (W)) (b) specimens

Table 2 Conversion of $\mathrm{NiCl}_{2}$ and $\mathrm{SiCl}_{4}$

\begin{tabular}{|c|c|c|c|c|c|c|c|c|c|c|}
\hline \multirow[b]{2}{*}{ Catalyst } & \multirow[b]{2}{*}{$\begin{array}{c}\mathrm{Ni} \text { Content } \\
{[\mathrm{wt} \%]}\end{array}$} & \multicolumn{4}{|c|}{ Inlet } & \multicolumn{3}{|c|}{ Outlet } & \multicolumn{2}{|c|}{ Conversion } \\
\hline & & {$\left[10^{-3}\right.$} & $\begin{array}{l}{\left[\beta_{0}\right]} \\
\mathrm{mol} / \mathrm{min}]\end{array}$ & {$\left[10^{-3}\right.$} & $\begin{array}{l}{\left[\alpha_{0}\right]} \\
\mathrm{mol} / \mathrm{min}]\end{array}$ & $\begin{array}{c}\mathrm{V}_{\mathrm{HCl}} \\
{\left[4\left(\alpha_{0}-\alpha\right)\right]} \\
{\left[10^{-3} \mathrm{~mol} / \mathrm{min}\right]}\end{array}$ & {$\left[10^{-3}\right.$} & $\begin{array}{l}{[2 \alpha+\beta]} \\
\mathrm{mol} / \mathrm{min}]\end{array}$ & $\begin{array}{c}\mathrm{NiCl}_{2} \\
\beta / \beta_{0} \\
{[-]}\end{array}$ & $\begin{array}{c}\mathrm{SiCl}_{4} \\
\alpha / \alpha_{0} \\
{[-]}\end{array}$ \\
\hline GN 3.4SI & 3.4 & & 0.29 & & 3.82 & 4.51 & & 5.51 & 0.414 & 0.705 \\
\hline GN 5.3SI & 5.3 & & 0.45 & & 3.82 & 4.54 & & 5.55 & 0.400 & 0.703 \\
\hline GN 8.7SI & 8.7 & & 1.30 & & 3.82 & 4.52 & & 6.09 & 0.546 & 0.704 \\
\hline GN 8.8SI & 8.8 & & 1.96 & & 3.82 & 3.85 & & 6.42 & 0.359 & 0.748 \\
\hline
\end{tabular}

Air flow rate $\left(\mathrm{V}_{\mathrm{A} i \mathrm{r}}\right)$ is $6.25 \times 10^{-2} \mathrm{~mol} / \mathrm{min}$ throughout this experiments

$\mathrm{NiCl}_{2}+\mathrm{SiCl}_{4}+\mathrm{O}_{2} \rightarrow \mathrm{NiO}+\mathrm{SiO}_{2}+\mathrm{Cl}_{2}$

$$
\underset{\left(\beta_{0}-\beta\right)}{\left(\alpha_{0}-\alpha\right)} \underset{\beta}{\alpha} \quad 2 \alpha+\beta
$$

の関係がある。また，第一段目のスクラバー中では次式 の反応は完結するので,

$$
\begin{aligned}
& \mathrm{SiCl}_{4}+\mathrm{H}_{2} \mathrm{O} \rightarrow \mathrm{SiO}_{2}+4 \mathrm{HCl} \\
& \left(\alpha_{0}-\alpha\right) \quad\left(\alpha_{0}-\alpha\right) \quad 4\left(\alpha_{0}-\alpha\right)
\end{aligned}
$$

となり, $a, b, \alpha, \beta$ の間には

$$
\begin{aligned}
& a=2 \alpha+\beta \\
& b=4\left(\alpha_{0}-\alpha\right)
\end{aligned}
$$

の関係が得られる.乙こで $b$ は単位時間当たりの未反応 $\mathrm{SiCl}_{4}$ の量に対応する. 乙れより Eqs. (6), (7)を解いて, $\mathrm{SiCl}_{4}$ および $\mathrm{NiCl}_{2}$ の転化率 $\alpha / \alpha_{0}$ および $\beta / \beta_{0}$ を求めた. その結果を Table 2 に示す。乙れより $\mathrm{SiCl}_{4}$ の転化率は

* $\mathrm{NiCl}_{2}$ 蒸気は反応器より下流の冷却器やスクラバーなどに 凝縮により付着するあのああるので, てれら付着物は反応終 了後集め, $\mathrm{NiCl}_{2}$ が水に可溶であることを利用して水洗前後 試料の原子吸光分析を行うことにより, 未反応 $\mathrm{NiCl}_{2}$ を測定 LEqs. (6)，(7) から求めた $\beta$ と比較, 検定を行い実験誤差 範网内で一致を見ている。
約 70 〜 $75 \%$ であるが, $\mathrm{NiCl}_{2}$ に関してはての操作条件の あとでは $\mathrm{NiCl}_{2}$ の供給流量が増すにしたがって $53 \%$ の転 化率から $35 \%$ に減じている. $\mathrm{SiCl}_{4}$ は約 $70 \%$ が転化して いた。

粒径と担持率 調製試料を $623 \mathrm{~K}$ で $3 \mathrm{~h}$ 水素還元後水 素吸着を行い, $S_{N i}, d_{N i}, D$ を求めた結果を Table 3 亿示 す. $\mathrm{Ni}$ 担持率を 3.4 から $8.8 \%$ 亿增加しても $\mathrm{Ni}$ 粒径, 分 散度はそれぞれ $3.2 \mathrm{~nm}$ および 25 ～ $28 \%$ とほとんど変化 していない，すなわち本調製法によると $\mathrm{Ni}$ 担持率を増 加させてあ $\mathrm{Ni}$ 粒径の増大は起きていない，したがって化 学気相析出法は噴霧熱分解法の時のように供給条件に 左右されずNi 成分を増加しても高分散度が保てると言 う意味で優れた触媒調製法である。

次に, $\mathrm{SiO}_{2}$ 上に分散している $\mathrm{NiO}$ の安定性を見るた め水素による還元温度を $623 \mathrm{~K}$ から $673 \mathrm{~K}, 723 \mathrm{~K}$ と変化 させてみた。 その結果も Table 3 に併せて示した。 それ によると担持率 $5.3 \%$ までは還元温度の上昇に伴う分散 
Table 3 Physical properites of washed specimen

\begin{tabular}{|c|c|c|c|c|c|}
\hline Catalyst & $\begin{array}{c}\text { Ni Content } \\
{[\%]} \\
\ldots \ldots \ldots \ldots \ldots \ldots . . . .\end{array}$ & $\begin{array}{l}\text { Reduction } \\
\text { Temp. [K] }\end{array}$ & $\begin{array}{c}S_{N i} \\
{\left[\mathrm{~m}^{2} / \mathrm{g}-\mathrm{cat}\right]}\end{array}$ & $\begin{array}{c}d_{N i} \\
{[\mathrm{~nm}]}\end{array}$ & $\begin{array}{c}D \\
{[\%]}\end{array}$ \\
\hline \multirow[t]{3}{*}{ GN 3.4SI- (W) } & 3.4 & 623 & 176.4 & 3.2 & 25.4 \\
\hline & & 673 & 184.0 & 3.0 & 28.6 \\
\hline & & 723 & 89.2 & 6.3 & .12 .8 \\
\hline \multirow[t]{4}{*}{ GN 5.3SI-(W) } & 5.3 & 623 & 181.4 & 3.1 & 26.1 \\
\hline & & 673 & 189.0 & 3.0 & 27.2 \\
\hline & & 723 & 137.8 & 4.1 & 19.8 \\
\hline & & 773 & 84.2 & 6.7 & 12.1 \\
\hline \multirow[t]{3}{*}{ GN 8.7SI-(W) } & 8.7 & 623 & 195.9 & 2.9 & 28.1 \\
\hline & & 673 & 145.0 & 3.9 & 20.9 \\
\hline & & 723 & 65.4 & 8.7 & 9.2 \\
\hline
\end{tabular}

度の減少はほとんど見られず $723 \mathrm{~K}$ で初めて見られる。 担持率が $8.7 \%$ になるとての傾向がやや著しくなる。

\section{Nomenclature}

$a=$ nickel chloride converted per unit time

$[\mathrm{mol} / \mathrm{min}]$

$b=$ amount of residual $\mathrm{SiCl}_{4}$ per unit time

$[\mathrm{mol} / \mathrm{min}]$

$D=$ extent of dispersion

$d_{N i}=$ diameter of nickel particle

$f=$ extent of reduction

$k^{\prime}=$ apparent reaction rate constant of $\mathrm{NiO}$ production

$N s=$ number of exposed nickel atom per unit weight of specimen

$N_{T}=$ number of total nickel atom per unit weight of specimen

$S_{N i}=$ specific surface area of nickel particle $\left[\mathrm{m}^{2} / \mathrm{g}\right]$

$T=$ temperature

$[\mathrm{K}]$

$V_{C_{2}}=$ flow rate of $\mathrm{Cl}_{2}$ at outlet of reactor

[ $\mathrm{mol} / \mathrm{min}]$

$V_{H}=$ amount of adsorbed hydrogen

$[\mathrm{mol} / \mathrm{g}]$
$V_{H C l}=$ production rate of $\mathrm{HCl}$ in scrabber $\mathrm{S}$

$[\mathrm{mol} / \mathrm{min}]$

$V_{\mathrm{SiCl}_{4}}=$ feed rate of $\mathrm{SiCl}_{4}$ at inlet of reactor

[ $\mathrm{mol} / \mathrm{min}]$

$W=$ nickel content

$\alpha=$ production rate of $\mathrm{NiO}$

$[\mathrm{mol} / \mathrm{min}]$

$\alpha_{0}=$ feed rate of $\mathrm{NiCl}_{2}$

$[\mathrm{mol} / \mathrm{min}]$

$\beta=$ production rate of $\mathrm{SiO}_{2}$

$[\mathrm{mol} / \mathrm{min}]$

$\beta_{0}=$ feed rate of $\mathrm{SiCl}_{4}$

$[\mathrm{mol} / \mathrm{min}]$

$\chi=$ mole fraction

\section{Literature cited}

1) Matsumoto. A, N. Sakamoto, J. Shiokawa, H. Tamura and T. Ishino: Kogyo kagaku zasshi, 70, 2115 (1967)

2) Ooi. H, Y. Tsugou, M. Yano and Y. Harano: Kagaku-kogaku Ronbunsyu, 15, 349 (1989)

3) Keraby. K: J. Amer. Chem. Soc., 58, 374 (1936)

4) Schafer. H, L. Bayer, G. Beil, K. Etzel and K. Kerhl: Z. Anorg. Allgem. Chem., 278, 300 (1955)

$5)$ Stull. D.R: Ind. Eng. Chem., 39, 540 (1947)

6) Tock. A.S, R. Wintgen, C. Somieski: Ber., 50, 175 (1917)

7) Wintgen. R: ibid., 52, 724 (1919) 


\title{
Preparation of $\mathrm{NiO} / \mathrm{SiO}_{2}$ Particles by Chemical Vapor Deposition
}

\author{
Hiroshi Ooi*, Atsuyuki OoTsuki**, Mototake Yano \\ and Yoshio Harano \\ Dept. of Applied Chem., Osaka City Univ., Osaka 558
}

Key Words : Chemical Vapor Deposition, Nickel Metal Catalyst, Catalyst Preparation, Nickel Fine Particle

Attempts to prepare $\mathrm{NiO} / \mathrm{SiO}$ specimens were successively performed by chemical vapor deposition (CVD). The starting materials were all gaseous components : nickel chloride $(\mathrm{g})$, silicone tetrachloride $(\mathrm{g})$ and oxygen.

In this method, highly dispersed $\mathrm{NiO}$ in a $\mathrm{SiO}_{2}$ matrix is more easily prepared than by chemical fumed deposition (CFD), which was previously performed by the thermal decomposition of nickel chloride/methanol fume in atmosphere. In this report, in contrast to the CFD method, it is found that the CVD method could reduce the diameter of supported $\mathrm{NiO}$ on $\mathrm{SiO}$ from $20 \sim 25 \mathrm{~nm}$ to $3 \sim 8 \mathrm{~nm}$ whilst the degree of dispersion could remain unchanged during the increase of nickel content from $3.4 \%$ to $8.8 \%$.

From the above facts, the CVD method is superior to other methods in that the nickel oxide particles were highly dispersed on the $\mathrm{SiO}_{2}$ matrix.

* Osaka Vocational School

** Ono Phermaceutical Industry Co. Ltd. 